\title{
DÜBLIN
}

Technological University Dublin

ARROW@TU Dublin

\section{A fast linear electro-optical effect in a non-chiral bent-core liquid crystal}

\author{
Yuri Panarin \\ Technological University Dublin, yuri.panarin@tudublin.ie
}

S.P. Sreenilayam

Trinity College Dublin, Ireland

J.K. Vij

Trinity College Dublin, Ireland, jvij@tcd.ie

See next page for additional authors

Follow this and additional works at: https://arrow.tudublin.ie/engscheleart2

Part of the Electrical and Computer Engineering Commons, and the Materials Chemistry Commons

\section{Recommended Citation}

Panarin, Yuri \& Sreenilayam, Sithara \& Vij, J. \& Lehman, Ann \& Tschierske, Carsten. (2017). Fast Linear Electro-optic effect in a Non-chiral bent-core Liquid Crystal. Journal of Materials Chemistry C. 5. 10.1039/ C7TC04820C.

This Article is brought to you for free and open access by the School of Electrical and Electronic Engineering at ARROW@TU Dublin. It has been accepted for inclusion in Articles by an authorized administrator of ARROW@TU Dublin. For more information, please contact arrow.admin@tudublin.ie, aisling.coyne@tudublin.ie, gerard.connolly@tudublin.ie.

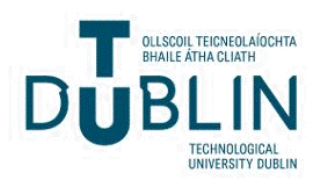




\section{Authors}

Yuri Panarin, S.P. Sreenilayam, J.K. Vij, A. Lehmann, and C. Tschierske

This article is available at ARROW@TU Dublin: https://arrow.tudublin.ie/engscheleart2/293 
Check for updates

Cite this: J. Mater. Chem. C, 2017, 5, 12585

Received 22nd October 2017, Accepted 6th November 2017

DOI: $10.1039 / c 7 t c 04820 c$

rsc.li/materials-c

\section{A fast linear electro-optical effect in a non-chiral bent-core liquid crystal}

\author{
Yu. P. Panarin, (D) ab S. P. Sreenilayam, ${ }^{a}$ J. K. Vij, (D) *a A. Lehmann ${ }^{c}$ and \\ C. Tschierske (D) ${ }^{c}$
}

\begin{abstract}
We report on the observation of an electro-optical effect for a linear rotation of the optical axis as a function of the electric field in an achiral tilted bent-core liquid crystalline compound, in which the 4-cyanoresorcinol bisbenzoate core is symmetrically terminated by long linear alkyl chains $(n=16)$ on both ends. The linear electro-optical effect observed in this material is similar to the deformed helical ferroelectric liquid crystal (DHFLC) effect reported previously in a FLC material except that dimensions of the helical pitch differ by two orders of magnitude. In a chiral system, the helical pitch usually lies on the scale of sub-optical wavelength, $\sim 0.3 \mu \mathrm{m}$, depending on the material and the temperature, whereas in an achiral system, the pitch lies on the nm scale. The DHFLC mode shows fast, analog switching due to a gradual distortion of the uniform helical structure by the electric field; the switching speed is faster than that for the chiral system. In contrast to the chiral FLCs, achiral liquid crystalline materials appear to be better candidates for applications in displays and photonic technologies.
\end{abstract}

\section{Introduction}

Liquid crystals (LCs) exhibit numerous liquid crystalline phases depending on the shape of the constituent molecules and the temperature. However, the most successful materials used so far in the LC display industry have been the nematic liquid crystals. The elongated shaped molecules form calamitic mesogens in nematics. With applications requiring higher switching speeds, use of nematics in devices in future is severely restricted especially due to their slow relaxation time $(\sim 1 \mathrm{~ms})$, which cannot be controlled by the electric field. The calamitic LCs may also exhibit SmA, tilted SmC and other analogous phases. The tilted smectics when composed of chiral molecules exhibit inlayer spontaneous polarization and form ferroelectric $\mathrm{SmC}^{*}$ and antiferroelectric $\mathrm{SmC}_{\mathrm{A}}{ }^{*}$ and a number of ferrielectric subphases. The latter emerge in between the temperatures of the two main phases $\mathrm{SmC}^{*}$ and $\mathrm{SmC}_{\mathrm{A}}{ }^{*}$.

Another class of LCs built from achiral bent-core (BC) molecules, though discovered several decades ago, ${ }^{1}$ has recently acquired greater interest from the LC community ${ }^{2,3}$ due to the interplay between polarity and chirality. Unlike calamitic LCs, the bent-core compounds even being non-chiral (achiral) may

\footnotetext{
${ }^{a}$ Department of Electronic and Electrical Engineering, Trinity College Dublin, The University of Dublin, Dublin 2, Ireland. E-mail: jvij@tcd.ie

${ }^{b}$ School of Electrical and Electronic Engineering, Dublin Institute of Technology, Dublin, Ireland

${ }^{c}$ Institute of Chemistry, Organic Chemistry, Martin-Luther-University Halle-Wittenberg, Germany
}

exhibit both spontaneous polarization and biaxiality in orthogonal (SmA-like) ${ }^{4,5}$ and tilted smectic (SmC-like) ${ }^{6,7}$ phases. Temperature dependences of both primary and secondary (i.e. biaxial) order parameters in orthogonal bent-core phases have been studied $^{7-9}$ and materials with these characteristics show promising applications in fast switching electro-optical devices. ${ }^{10-12}$ These non-tilted smectic (or orthogonal) phases incorporating achiral molecules have $C_{2 \mathrm{v}}$ symmetry. These phases display a large inlayer polarization as well as biaxiality.

The bent-core systems also exhibit a rich polymorphism of tilted smectic and modulated smectic phases. At least seven major phases have been observed., ${ }^{3,13-16}$ These were classified as B1-B7 at the "Workshop on Banana-Shaped Liquid Crystals: Chirality by Achiral Molecules", held in Berlin in 1997. One of such phases is B2, which is a tilted SmC-like phase with a large inlayer spontaneous polarization. ${ }^{7}$ In $\mathrm{B} 2$, the molecular bent planes are tilted in a direction perpendicular to the inlayer polarization vector either to the left or to the right with respect to the layer normal, giving rise to chiral $C_{2}$ symmetric layers. ${ }^{17-19}$ There exist four possibilities of molecular orientation in the neighboring layers: synclinic/anticlinic with respect to the tilt direction and ferroelectric/antiferroelectric with respect to the spontaneous polarization vectors. These can form a total of four structural arrangements: ${ }^{7} \mathrm{SmC}_{\mathrm{S}} \mathrm{P}_{\mathrm{F}}, \mathrm{SmC}_{\mathrm{A}} \mathrm{P}_{\mathrm{A}}, \mathrm{SmC}_{\mathrm{S}} \mathrm{P}_{\mathrm{A}}$, and $\mathrm{SmC}_{\mathrm{A}} \mathrm{P}_{\mathrm{F}}$. The first two polar structures are chiral, and the last two structural arrangements are racemic. The characteristics and structures of the bent-core LC systems are detailed in ref. 20 and 21. The electro-optical switching of the bent-core LCs has been investigated mainly in the $\mathrm{B} 2$ (SmCP) phase by a 


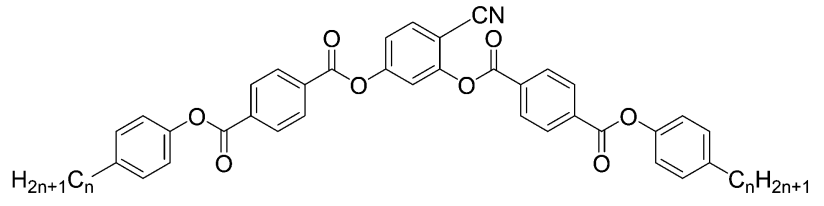

1/16 $(n=16): \mathrm{Cr} 77 \mathrm{SmCP}_{\mathrm{A}} 90 \mathrm{SmC}_{\mathrm{S}} \mathrm{P}_{\mathrm{F}}$ hel $110 \mathrm{SmC}_{\mathrm{S}} 125 \mathrm{SmA} 162$ Iso $\left(T /{ }^{\circ} \mathrm{C}\right)$

Fig. 1 Molecular structure of a homologous series of 4-cyanoresorcinol bisbenzoate with two terephthalate based wings terminated by alkyl chains, phases and the phase-transition temperature on cooling from the isotropic phase for $1 / n=1 / 16$.

number of authors. ${ }^{7,13,15,22-27}$ Nevertheless no significant potential application of this tilted phase has so far been reported mainly due to the major difficulty in obtaining 'a good homogeneous planar alignment'. In this paper, we report on the observation of new fast electro-optical switching, with a high-contrast ratio in between the on/off states, with an electric field applied across a planar-aligned cell of an achiral bent-core LC in its tilted smectic B2 phase.

The bent-core materials under study belong to a homologous series of 4-cyanoresorcinol bisbenzoate with two terephthalate based wings, whose ends are terminated by symmetric alkyl chains on both sides. The molecular structure of this series is shown in Fig. 1. Compounds with $n=2$ to 12 are known to form a number of orthogonal SmA like phases, ${ }^{8,9,11}$ while materials with longer alkyl tails may exhibit tilted SmC-like B2-phases.

In this paper we report on the results of the EO study of a compound, $1 / n=1 / 16$, that belongs to a homologous series that exhibits the phase sequence shown in Fig. 1.

\section{Experimental}

The electro-optical response of planar-aligned cells is investigated. This is studied by spin-coating ITO deposited substrates using polymer solution RN 1175 (Nissan chemicals, Japan). This solution is polymerized by baking the solution treated substrates in an oven at a temperature of $250{ }^{\circ} \mathrm{C}$ for 1 hour. Both substrates of a cell are rubbed using a commercial rubbing machine in a well-defined direction, denoted as the rubbing direction. The distance of separation between the two electrodes is controlled by Mylar spacers of different thicknesses; the cell separation is measured by an optical interference technique. The electro-optical effect is studied using a Polarizing Optical Microscope (POM, Olympus BX 52) equipped with an INSTEC's hot stage connected to a temperature controller (Eurotherm 2604) which allows stabilization of the sample temperature to within $\pm 0.02{ }^{\circ} \mathrm{C}$.

\section{Results and discussion}

Phase identification as discussed in ref. 28 is done by comparing the polarizing microphotographs of planar and homeotropicaligned LC cells, both in the absence and presence of an applied external field. The cells in both cases were cooled systematically from the isotropic phase. At the isotropic-Sm like phase transition, the cells show textures typical of a conventional SmA phase, i.e. the planar cell shows a homogeneous texture, in which the optical axis in the cell is directed along the rubbing direction, while the homeotropic cell shows perfect extinction of a beam of light incident on the cell under crossed polarizers due to the uniaxial orthogonal nature of the phase. Emergence of an orthogonal SmA phase below the isotropic phase is an important feature of these compounds; it would appear that the SmA phase is mainly responsible for obtaining a perfect homogeneous alignment in the tilted SmCP (B2) phases. Furthermore, the homogeneous texture exhibited by the planar-aligned cell in the SmA phase is retained on cooling at the phase transitions to the tilted phases.

On cooling the sample to a temperature of $130{ }^{\circ} \mathrm{C}$, the existing uniform texture breaks into two sets of domains with the optical axis tilted by angle $\pm \theta$, from the rubbing direction; the magnitude of $\theta$ depends on the temperature. A Schlieren texture is exhibited by the homeotropic-aligned cell due to the emergence of the molecular tilt. Such a texture is typical of the synclinic tilted $\mathrm{SmC}_{\mathrm{S}} \mathrm{P}$ type phases and more importantly this texture does not respond to the applied electric field, suggesting it to be a conventional non-chiral SmC phase or a tilted $\mathrm{SmC}_{S} \mathrm{P}_{\mathrm{R}}$ phase where the polarization vectors are randomly distributed. ${ }^{29}$ This phase can also be thought of as a tilted analog of a previously reported $\mathrm{SmAP}_{\mathrm{R}}$ phase..$^{30}$ On cooling the sample further, chiral domains in the planar-aligned cell and the Schlieren texture exhibited by the homeotropic-aligned cell become increasingly dominant due to a gradual increase in the tilt angle $\theta$ with a reduction in temperature. The tilt angle in the materials saturates at an angle of $\sim 18^{\circ}$. A change in birefringence in planar-aligned cells allows for a gradual change in color from green to red due to an increase in the nematic order parameter upon reducing the temperature.

At the phase transition temperature of $110{ }^{\circ} \mathrm{C}$, the texture suddenly changes back to mono-domain uniaxial; this leads to a large extinction of light in the homeotropic cell. In other words, the texture of homeotropic cells is like that of the SmA phase uniformly black. In the absence of a voltage signal applied across the planar-aligned cell, the texture appears identical to that of the SmA phase. The phase transition is also characterized by a significant reduction in birefringence $(\sim 17 \%)$ from $\sim 0.109$ to $\sim 0.091$ (see Fig. 2(a)). Such a uniaxial and a low-birefringence state can be explained through the emergence of the helical structure in the polar and tilted smectic SmCP phase, whose helical pitch is shorter than the optical wavelength. This is explained as follows: the effective birefringence is given by $\Delta n_{\text {eff }}(\theta)=\frac{\Delta n_{0}}{2}\left(3 \cos ^{2} \theta-1\right),,^{31}$ where $\Delta n_{0}$ is the birefringence of the unwound synclinic structure. The helical structure has already been confirmed through direct imaging of the pattern of the helical structure that is formed using an Atomic Force Microscope (AFM). From these measurements, helical pitch $p_{0}$ at $105{ }^{\circ} \mathrm{C}$ is obtained to be of the order of $15 \mathrm{~nm} .{ }^{28}$

In the absence of the electric field applied across the planaraligned cell, the average direction of molecular long axes i.e. the director is tilted by angle $\theta$, and the azimuthal angle, $\varphi(z)$, varies linearly along the smectic layer normal, $z$, as $2 \pi z / p_{0}$, 


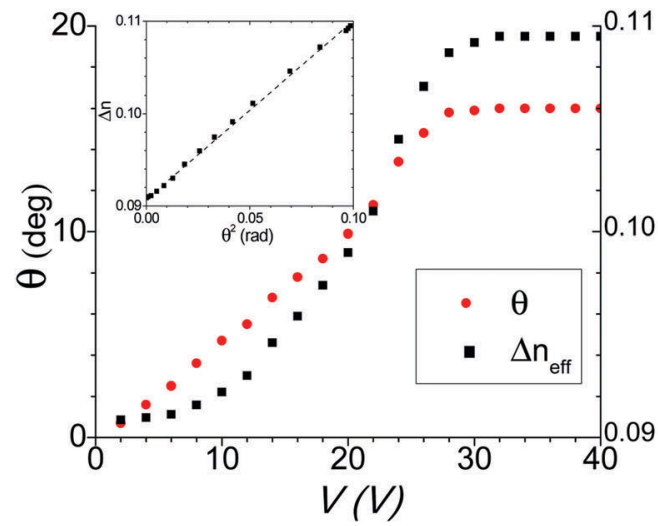

(a)

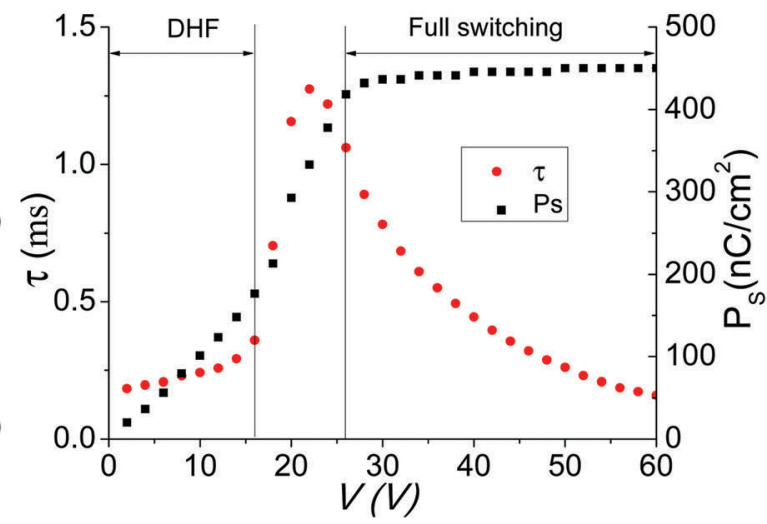

(b)

Fig. 2 (a) Voltage dependences of switching (induced) angle $(\mathbf{O})$ and birefringence ( $\mathbf{\square})$ in a $9 \mu \mathrm{m}$ planar-aligned cell in response to a $100 \mathrm{~Hz}$ squarewave signal, inset: birefringence plotted vs. square of the induced optical angle, (b) voltage dependence of the induced/spontaneous polarization ( $)$ and the switching time $(\mathbf{\square})$ at $105^{\circ} \mathrm{C}$.

with a uniform distribution function, $f(\varphi)=1 / p_{0}$, of the directors distributed on a cone about $z$. Thus this forms an optically uniaxial structure where the optical axis lies parallel to the helical axis and along the smectic layer normal in the planar-aligned cell. Application of the electric field across the planar-aligned cell gradually deforms the helix; the optical axis is rotated from the layer normal (the rubbing direction) by an angle $\theta_{\text {ind }}(E)$ depending on the field. The birefringence shown in Fig. 2(a) is also increased by the field. The electro-optical response observed here is similar to that of the 'Deformed Helical' (DH) mode observed in the chiral SmC* phase of Ferroelectric Liquid Crystals (FLC). ${ }^{32,33}$ A study of the deformation of the helix by an applied electric field has been reported by a number of authors. ${ }^{34-36}$ According to these investigations, the induced optical angle is proportional to the electric field $(\sim E)$ while the change in the effective birefringence is proportional to $E^{2}$. This is illustrated in the inset of Fig. 2(a) where the effective birefringence changes linearly with the square of the induced optical tilt angle.

The field-induced helical distortion leads to the emergence of a net spontaneous polarization, which is shown in Fig. 2(b). The induced/net polarization was calculated using the technique of integrating the switching current with time flowing through the circuit. Application of the external voltage causes reorientation of the $P_{\mathrm{S}}$ vector, which gives rise to a flow of current through the cell. The voltage across the capacitor, $V_{\mathrm{p}}$, is proportional to the integral of this current and this therefore yields the net/switching spontaneous polarization $\left(P_{\mathrm{s}}\right)$ as $P_{\mathrm{S}}=V_{\mathrm{p}} \cdot C /(2 S),{ }^{37}$ where $S$ is the area of electrodes and $C$ is the capacitance of the cell in the material.

Fig. 2b shows voltage dependences of the induced/spontaneous polarization ( $(\boldsymbol{\square})$ and the switching time $(\bullet)$ measured at a temperature of $105{ }^{\circ} \mathrm{C}$ for an $8 \mu \mathrm{m}$ cell. Initially for voltages $<20 \mathrm{~V}$, the measured spontaneous polarization is proportional to the applied voltage. This is similar to the dependence of the optical switching angle on the voltage but the polarization switching time is almost constant, in agreement with that for the DHFLC mode. ${ }^{32,33}$ Upon a further increase in the applied voltage, three parameters, $\Delta n, \theta_{\text {ind }}, P_{\mathrm{s}}$, saturate to their maximum values with voltage; these three emerge from helical unwinding by the field, while the switching time decreases inversely with the electric field, in close agreement with the FLC switching dynamics. ${ }^{37}$ In the intermediate range of the applied voltage (17-26 V) between the low- and high-electric field regimes, both switching modes can coexist.

Two different geometries exist for the study of the electrooptical response of the DHF mode to the field depending on angle $\psi$ between the axis of the polarizer and the smectic layer normal (or the rubbing direction): (i) $\psi=0^{\circ}$ shows the quadratic mode and (ii) $\psi=22.5^{\circ}$ shows the linear mode. Fig. 3 shows the electro-optical response and the POM textures following the application of a triangular waveform across the planar-aligned cell. This corresponds to a different magnitude of voltage in the quadratic mode, $\psi=0^{\circ}$. At $0 \mathrm{~V}$, the optical axis is oriented along the crossed polarizer/analyzer axis and the cell exhibits a large extinction of light (dark state). With an increase in the applied voltage, the optical axis initially rotates linearly by an angle $\theta_{\text {ind }}$ with the field. This results in an increase in the

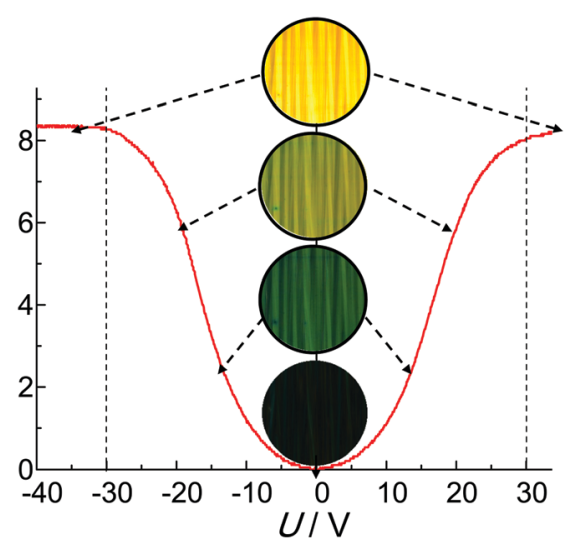

Fig. 3 Electro-optical response of an $8 \mu \mathrm{m}$ planar LC cell subjected to an applied voltage of $80 \mathrm{~V}_{\mathrm{p}-\mathrm{p}}$ at a frequency of $100 \mathrm{~Hz}$, a triangular applied voltage and the POM textures for different applied voltages. 
transmittance of light by the square law such that $T \sim \sin ^{2}\left(\theta_{\text {ind }}\right)$ $\approx \theta_{\text {ind }}{ }^{2}[\sin \theta \approx \theta$ for small values of $\theta]$. Further increase in the applied voltage causes the helix to unwind and the transmittance to finally reach saturation. Finally the electro-optical response is observed to be V-shaped with an analog gray scale, i.e. the amplitude of transmittance increases gradually with the field. The contrast ratio between the bright and dark states is of the order of $\sim 300$ depending on the temperature. Such a thresholdless, V-shaped electro-optical response is an attractive feature of this new type of LC display.

The second, linear electro-optical mode is realized when the cell is rotated such that the smectic layer normal and the polarizer or the analyzer in the system of crossed polarizers are fixed at an angle of $\psi=22.5^{\circ}$. Fig. 4 shows the dynamics of the DHFLC, polarization is expressed in terms of the voltage signal, the EO response is given as a function of time, the planar-aligned LC cell with thickness $8 \mu \mathrm{m}$ is subjected to $20 \mathrm{~V}$, and a $500 \mathrm{~Hz}$ square-wave signal. The temperature of the cell is fixed at $105{ }^{\circ} \mathrm{C}$ in its $\mathrm{SmC}_{\mathrm{S}} \mathrm{P}_{\mathrm{F}}^{\text {hel }}$ phase. The voltage signal, $V_{\mathrm{p}}(t)$, due to the polarization and the EO response are similar to each other, and both of these allow us to measure the dynamics and amplitude characteristics of the DHF mode. It is shown that the polarization switching time, $t_{\mathrm{p}}$, is $26 \%$ longer than the switching time (10-90\%) observed from the EO response. The repolarization

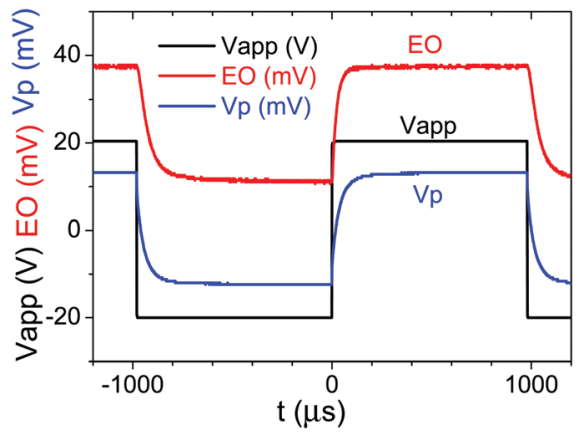

Fig. 4 Dynamics of the switching polarization voltage $\left(V_{p}\right.$ as a function of t) and the electro-optical response (EO) to the applied square-wave signal of amplitude $20 \mathrm{~V}, f=500 \mathrm{~Hz}$ measured in an $8 \mu \mathrm{m}$ planar-aligned LC cell at a temperature of $105^{\circ} \mathrm{C}$. method produces more robust and reliable results than the EO technique, since it is not dependent on the optical retardation, $\pi \cdot \Delta n \cdot d / \lambda$, alignment quality and cell orientation (i.e. $\psi$ angle). ${ }^{37}$ Therefore, hereafter, we use the repolarization current technique to study the dynamic properties of the DHF effect.

Another problem encountered by the EO technique is the emergence of two sets of domains of opposite chirality in the $\mathrm{SmC}_{\mathrm{S}} \mathrm{P}_{\mathrm{F}}$ phase. Switching with the field takes place in the opposite sense. Initially, electro-optical switching of the two-domains is observed but this does not affect the measurements of the switching current. Then during several minutes of continuous switching of the cell by the field, one of the two chiral domains gradually disappears while the second with opposite chirality grows. ${ }^{38}$ This results in an optically uniform mono-domain texture.

Dynamic properties of a planar-aligned LC cell containing the bent-core LC are investigated as a function of amplitude and frequency of the applied square-wave voltage signal at different temperatures in the temperature range of $110-80{ }^{\circ} \mathrm{C}$, under cooling. The frequency range of the applied signal is $100 \mathrm{~Hz}-1 \mathrm{kHz}$. The frequency is large enough to avoid parasitic effects of ionic dynamics that occur while it is low enough for enabling full switching to occur, Fig. 4. The magnitude of the applied square-wave voltage is varied between $2 \mathrm{~V}$ and $60 \mathrm{~V}$ with a voltage step of 2 V. Fig. 5 shows the temperature dependences of (a) switching polarization and (b) switching time (10-90\%) measured for different applied voltages and a $100 \mathrm{~Hz}$ square-wave signal applied across a planar-aligned cell with thickness $8 \mu \mathrm{m}$.

As shown in Fig. 5a, for voltages $\geq 50 \mathrm{~V}$, the net spontaneous polarization typically increases on cooling. The result is based on the assumption that a complete polarization switching occurs with the magnitude of the voltage that has been applied. In contrast, for a voltage signal of $\leq 15 \mathrm{~V}$, the switched polarization is considerably lower than the maximum saturated spontaneous polarization and this decreases somewhat upon cooling, which is a typical feature of the DHF mode. In the middle voltage range, $15 \mathrm{~V} \leq V \leq 60 \mathrm{~V}$, the full spontaneous polarization switching at higher temperatures transforms to the helical DHF mode at lower temperatures upon cooling. In other words, the helix can be easily unwound at higher temperatures since the threshold field for helical unwinding decreases with an

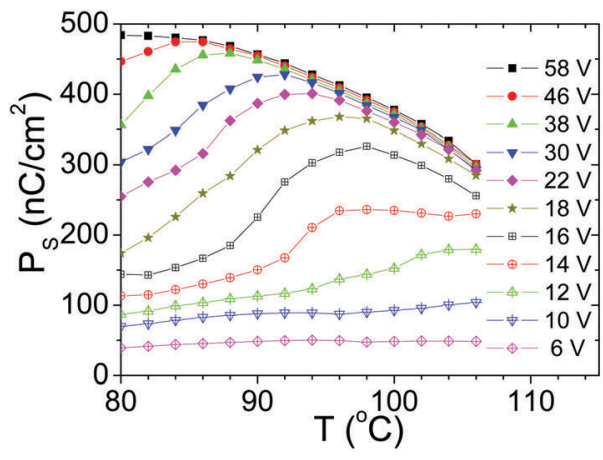

(a)

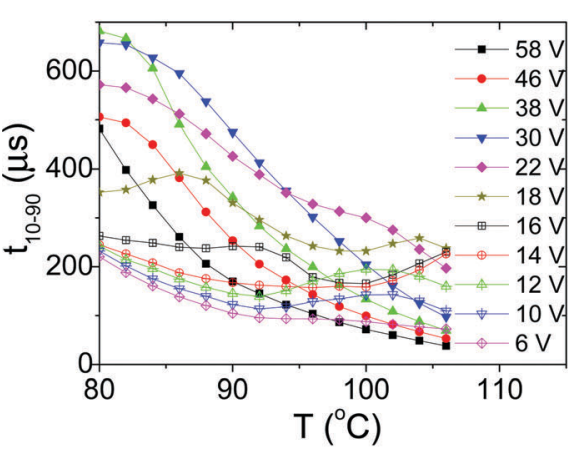

(b)

Fig. 5 (a) Temperature dependence of (a) the switching polarization and (b) the switching time measured in a $8 \mu \mathrm{m}$ planar-aligned cell for different applied voltages at a frequency of a $100 \mathrm{~Hz}$ square-wave signal. 
increase in temperature. The switching time decreases inversely with the field (see Fig. 2b) and decreases with an increase in temperature: $\sim 500 \mu \mathrm{s}$ at $80{ }^{\circ} \mathrm{C}$ to $\sim 40 \mu \mathrm{s}$ at $105{ }^{\circ} \mathrm{C}$. In the low field/voltage range that corresponds to the DHF mode, the switching time is weakly dependent on the voltage and temperature, $\sim 220 \mu \mathrm{s}$ at $80{ }^{\circ} \mathrm{C}$ to $\sim 70 \mu \mathrm{s}$ at $105{ }^{\circ} \mathrm{C}$. In an intermediate field/voltage range, the switching time shows a more complicated behavior due to a gradual transformation from the full switching mode to the DHF mode under cooling.

The discovery of the DHFLC in the late 1980s has led to an increased interest in its use in faster switching devices. Some of the examples are (i) tunable gray-scale electro-optical modulators; ${ }^{33}$ (ii) spatial light modulators (SLM); ${ }^{39}$ (iii) highly desirable color-sequential LC displays; ${ }^{40}$ and (iv) the optic fiber sensors. ${ }^{41}$ Better DHFLC electro-optical characteristics were achieved using FLC materials having a tilt angle of $>25^{\circ}$ and a short (sub-optical) helical pitch. The switching time $\tau$ is given by the equation

$$
\tau=\frac{\gamma}{K_{22} q^{2}}
$$

where $\gamma$ is the rotational viscosity, $K_{22}$ is the twist elastic constant and $q$ is the wave vector, $q=\frac{2 \pi}{p}$, where $p$ is the helical pitch. It should be noted that the previously reported DHFLC studies were conducted only using chiral molecular systems with a large enantiomeric excess. In contrast, the bent-core materials are achiral but are easy to synthesize and are relatively inexpensive. These exhibit a faster switching time due to the shorter helical pitch and a large temperature independent tilt angle. This is therefore the first example of the observation and successful demonstration of the DHF mode in an achiral system. The results also indirectly confirm the existence of the helical state in the $\mathrm{SmC}_{\mathrm{S}} \mathrm{P}_{\mathrm{F}}$ phase of an achiral compound. Exploitation of these properties makes the achiral bent-core LCs prospective better candidates for high-speed, grey-scale applications in LCDs, SLMs, and electro-optical shutters.

\section{Conclusions}

In summary, we observe a linear electro-optical effect in an achiral tilted (SmCP) bent-core system. The tilt angle induced by the field is linearly related to the electric field. The effect is identified as the DHFLC effect in the $\operatorname{SmC}_{S} P_{F}$ phase of achiral bent-core systems and is similar to that reported previously for FLC chiral materials where the pitch lies in the sub-optical wavelength region. In this work, the helical pitch is much shorter than the wavelength of light and lies on the nm length scale. The mode shows grey-scale switching due to helical deformation of the short pitch by the field. The speed is faster than that for the chiral FLCs. In addition, the achiral LCs are (i) inexpensive, (ii) easy to synthesize and (iii) better candidates for prospective applications in displays and photonic technologies. Innovative solutions in molecular engineering and synthesis techniques are required to bring down the operating temperature range of the achiral bent-core liquid crystalline materials as well as to develop mixtures to widen the useful temperature range of the devices.

\section{Conflicts of interest}

There is no conflict of interest to declare.

\section{Acknowledgements}

Our work was partly supported by 13/US/I2866 from the Science Foundation Ireland as part of the US-Ireland Research and Development Partnership Program jointly administered by the United States National Science Foundation under grant number NSF-DMR-1410649.

\section{References}

1 D. Vorlander, Ber. Dtsch. Chem. Ges., 1929, 62, 2831.

2 M. Kuboshita, Y. Matsunaga and H. Matsuzaki, Mol. Cryst. Liq. Cryst., 1991, 199, 319-326.

3 T. Niori, T. Sekine, J. Watanabe, T. Furukawa and H. Takezoe, J. Mater. Chem., 1996, 6, 1231-1233.

4 K. J. K. Semmler, T. J. Dingemans and E. T. Samulski, Liq. Cryst., 1998, 24, 799-803.

5 A. Eremin, S. Diele, G. Pelzl, H. Nadasi, J. Salfetnikova, W. Weissflog and H. Kresse, Phys. Rev. E: Stat., Nonlinear, Soft Matter Phys., 2001, 64, 051707.

6 T. Sekine, Y. Takanishi, T. Niori, J. Watanabe and H. Takezoe, Jpn. J. Appl. Phys., 1997, 36, L1201-L1203.

7 D. R. Link, G. Natale, R. Shao, J. E. Maclennan, N. A. Clark, E. Korblova and D. M. Walba, Science, 1997, 278, 1924-1927.

8 S. Sreenilayam, Yu. P. Panarin, J. K. Vij, M. Osipov, A. Lehmann and C. Tschierske, Phys. Rev. E: Stat., Nonlinear, Soft Matter Phys., 2013, 88, 021504.

9 Yu. P. Panarin, M. Nagaraj, J. K. Vij, C. Keith and C. Tschierske, EPL, 2010, 92, 26002.

10 Y. Shimbo, Y. Takanishi, K. Ishikawa, E. Gorecka, D. Pociecha, J. Mieczkowski, K. Gomola and H. Takezoe, Jpn. J. Appl. Phys., 2006, 45, L282-L284.

11 M. Nagaraj, Yu. P. Panarin, J. K. Vij, C. Keith and C. Tschierske, Appl. Phys. Lett., 2010, 97, 213505.

12 Y. Shen, L. Goodhew, R. Shao, M. Moran, E. Korblova, D. M. Walba, N. A. Clark, J. E. Maclennan and P. Rudquist, Appl. Phys. Lett., 2015, 106, 191101.

13 T. Sekine, T. Niori, J. Watanabe, T. Furukawa, S.-W. Choi and H. Takezoe, J. Mater. Chem., 1997, 7, 1307-1309.

14 J. Watanabe, T. Niori, T. Sekine and H. Takezoe, Jpn. J. Appl. Phys., 1998, 37, L139-L142.

15 G. Pelzl, S. Diele and W. Weissflog, Adv. Mater., 1999, 11, 707-724.

16 G. Pelzl, S. Diele, A. Jakli, Ch. Lischka, I. Wirth and W. Weissflog, Liq. Cryst., 1999, 26, 135-139.

17 A. Jakli, G. G. Nair, C. K. Lee, R. Sun and L. C. Chien, Phys. Rev. E: Stat., Nonlinear, Soft Matter Phys., 2001, 63, 061710.

18 D. M. Walba, E. Korblova, R. Shao, J. E. Maclennan, D. R. Link, M. A. Glaser and N. A. Clark, Science, 2000, 288, 2181-2184. 
19 M. Nakata, D. R. Link, F. Araoka, J. Thisayukta, Y. Takanishi, K. Ishikawa, J. Watanabe and H. Takezoe, Liq. Cryst., 2001, 28, 1301-1308.

20 R. A. Reddy and C. Tschierske, J. Mater. Chem., 2006, 16, 907-961.

21 H. Takezoe and Y. Takanishi, Jpn. J. Appl. Phys., 2006, 45, 597-625.

22 G. Heppke, A. Jakli, S. Rauch and H. Sawade, Phys. Rev. E: Stat., Nonlinear, Soft Matter Phys., 1999, 60, 5575-5579.

23 M. Zennyoji, Y. Takanishi, K. Ishikawa, J. Thisayukta, J. Watanabe and H. Takezoe, J. Mater. Chem., 1999, 9, 2775-2778.

24 G. Dantlgraber, A. Eremin, S. Diele, A. Hauser, H. Kresse, G. Pelzl and C. Tschierske, Angew. Chem., Int. Ed., 2002, 41, 2408-2412.

25 L. M. Blinov, M. I. Barnik, E. S. Bustamante, G. Pelzl and W. Weissflog, Phys. Rev. E: Stat., Nonlinear, Soft Matter Phys., 2003, 67, 021706.

26 M. Nakata, R.-F. Shao, J. E. Maclennan, W. Weissflog and N. A. Clark, Phys. Rev. Lett., 2006, 96, 067802.

27 M. Nakata, D. Chen, R. Shao, E. Korblova, J. E. Maclennan, D. M. Walba and N. A. Clark, Phys. Rev. E: Stat., Nonlinear, Soft Matter Phys., 2012, 85, 031704.

28 S. P. Sreenilayam, Yu. P. Panarin, J. K. Vij, V. P. Panov, A. Lehmann, M. Poppe, M. Prehm and C. Tschierske, Nat. Commun., 2016, 7, 11369.

29 M. Alaasar, M. Prehm, M. Nagaraj, J. K. Vij and C. Tschierske, Adv. Mater., 2013, 25, 2186-2191.
30 D. Pociecha, M. Cepic, E. Gorecka and J. Mieczkowski, Phys. Rev. Lett., 2003, 91, 185501.

31 N. A. Clark, T. Bellini, R.-F. Shao, D. Coleman, S. Bardon, D. R. Link, J. E. Maclennan, X.-H. Chen, M. D. Wand, D. M. Walba, P. Rudquist and S. T. Largerwall, Appl. Phys. Lett., 2002, 80, 4097.

32 L. A. Beresnev, V. G. Chigrinov, D. I. Dergachev, E. P. Pozhidaev, J. Funfschilling and M. Schadt, Liq. Cryst., 1989, 5, 1171-1177.

33 Yu. P. Panarin, E. Pozhidaev and V. Chigrinov, Ferroelectrics, 1991, 114, 181-186.

34 I. Abdulhalim and G. Moddel, Mol. Cryst. Liq. Cryst., 1991, 200, 79-101.

35 E. P. Pozhidaev, A. D. Kiselev, A. K. Srivastava, V. G. Chigrinov, H.-S. Kwok and M. V. Minchenko, Phys. Rev. E: Stat., Nonlinear, Soft Matter Phys., 2013, 87, 052502.

36 A. D. Kiselev and V. G. Chigrinov, Phys. Rev. E: Stat., Nonlinear, Soft Matter Phys., 2014, 90, 042504.

37 V. M. Vaksman and Yu. P. Panarin, Mol. Mats., 1992, 1, 147-154.

38 N. A. Clark and S. T. Lagerwall, Appl. Phys. Lett., 1980, 36, 899-901.

39 L. A. Beresnev, L. M. Blinov, D. I. Dergachev, A. I. Zhindulis, I. S. Klimenko, S. I. Paedea and A. A. Sergeev, Sov. Technol. Phys. Lett., 1988, 14, 116.

40 G. Hedge, P. Xu, E. Pozhidaev, V. Chigrinov and H. S. Kwok, Liq. Cryst., 2008, 35, 1137-1144.

41 Z. Brodzeli, L. Silvestri, A. Michie, V. Chigrinov, Q. Guo, E. P. Pozhidaev, A. D. Kiselev and F. Ladouceur, Photonic Sens., 2012, 2, 237-246. 